\title{
Induction and retention of kinesthetic aftereffects as a function of number and distribution of inspection trials'
}

\author{
PAUL BAKAN, MICHIGAN STATE UNIVERSITY \\ RICHARD W. THOMPSON, OHIO UNIVERSITY
}

Measures of kinesthetic aftereffects were made for $240 \mathrm{Ss}$ in 15 groups. Each group was tested with a combination of number of 30-sec. inspection periods $(5,10$, or 15) and time between inspection periods $(0,10,30,60$, or $90 \mathrm{sec})$. The number of inspection periods had a significant effect on size of aftereffect and on residual aftereffect $15 \mathrm{~min}$ later. The maximum aftereffect followed the 10 period inspection $(5 \mathrm{~min}$ inspection). Distribution of inspection periods in time had no significant effect on these measures of aftereffect. In a second experiment, distribution of inspection periods in time had no effect on induced aftereffect or on residual aftereffect $24 \mathrm{~h}$ later. There was significant residual aftereffect after $24 \mathrm{~h}$ which was significantly related to amount of aftereffect originally induced.

The distribution over time of the total inspection time has been suggested as a determinant of the size and retention of perceptual aftereffects (Köhler \& Fishback, 1950a, b; Duncan, 1956). On the basis of a study designed to investigate the effect of different distributions of total inspection time on kinesthetic aftereffects (KAE), Carlson (1963) concludes that "distributing inspection time per se does not necessarily lead to a greater initial effect than if the same total amount of I-time is given in a single massed period." Furthermore, she finds no evidence that distribution of inspection time has any effect on retention of the KAE.

This conclusion is based on only one condition of distribution of the total I-period, namely 1-min. Iperiods separated by $2-\mathrm{min}$. rest periods. It is conceivable that other distribution programs would give different results. In the present study the effect of distribution of inspection time was studied under four different spaced conditions and a massed condition for three different amounts of total inspection time. Another significant procedural difference is that in the present study the KAE was an apparent expansion of the $\mathrm{T}$-block after exposure to an I-block narrower than the T-block, whereas Carlson studied a KAE of apparent shrinkage of the T-block after exposure to an I-block wider than the T-block.

\section{EXPERIMENT 1}

\section{Method}

Design. Measures of KAE were taken on 240 undergraduate Ss divided randomly into 15 groups of 16 each. In a factorial design each group was treated with a different combination of 30-sec. I-periods (5, 10, or 15 I periods) and time between I-periods $(0,10,30,60$, or $90 \mathrm{sec}$.$) .$

Apparatus. The apparatus consisted of three wooden blocks: (1) a standard block with parallel sides 1.5 in. wide, 60 in. long, and 2 in. thick; (2) a tapered block (2 in. thick) varying in width from 1 in. to 2.875 in. at the rate of $1 / 32$ in. per in; and (3) an I-block with parallel sides 0.5 in. wide. This was 24 in. long and 2 in. thick. The blocks were mounted on tables 36 in. high and parallel to each other. The standard and I-block were at the side of S's non-preferred hand, and the variable block was at the side of S's preferred hand. The variable block was fitted with an H-shaped rider within which $\mathrm{S}$ placed the thumb and middle finger while making judgments of subjective equality. A blindfold was worn from the time that $S$ entered the experimental room.

Procedure. Ss made matches of apparent equality by finding a width on the tapered block subjectively equal to the width of the standard block in the other hand. Following instructions and kinesthetic exploration of the apparatus, $S$ made two practice matches, one from each end of the variable width block. $S$ could move in either direction on the block and was encouraged to "zero in" on the correct location. He then made four pre-inspection matches with alternating starting points (descending, D, or ascending, A). The mean of these matches constituted a preinspection PSE.

The inspection periods (I-periods) followed. Each I-period consisted of a 30-sec. back and forth motion with the non-preferred hand along the I-stimulus. The number of I-perlods and the time between them differed for the 15 experimental groups. Following inspection, four post-inspection judgments were made (DADA order) and the mean of these judgments constituted the post-inspection PSE. Fifteen min. later, four additional judgments were made and the mean of these constitutes a retention PSE. The difference between the pre- and post-PSE is the KAE; the difference between the pre- and retention-PSE is the retention KAE.

\section{Results}

For all groups the $\mathrm{KAE}$ and retention $\mathrm{KAE}$ can be described as an apparent increase in width of the standard stimulus after exposure to the I-stimulus. 
Table 1. Mean post-inspection and retention kinesthetic aftereffects (in.) for groups differing in combinations of inspection periods and time between periods.

\begin{tabular}{|c|c|c|c|c|c|c|c|}
\hline \multirow{3}{*}{$\begin{array}{l}\text { Time } \\
\text { between } \\
\text { periods } \\
\text { (sec) }\end{array}$} & \multicolumn{7}{|c|}{ Number of inspection periods ( $30 \mathrm{sec}$ each) } \\
\hline & Post & Reten- & Post & Reten- & Post $F$ & Reten- & \multirow[t]{2}{*}{ Mean } \\
\hline & In spectio & n tion & Inspection & tion & Inspection & tion & \\
\hline 0 & .10 & .09 & .21 & .14 & .11 & .09 & .12 \\
\hline 10 & .12 & .14 & .16 & .19 & .19 & .15 & .16 \\
\hline 30 & .13 & .15 & .22 & .16 & .17 & .21 & .17 \\
\hline 60 & .11 & .13 & .19 & .16 & .15 & .16 & .15 \\
\hline 90 & .11 & .09 & .23 & .21 & .17 & .15 & .16 \\
\hline Mean & .1 & & .19 & & .16 & & \\
\hline
\end{tabular}

The mean KAE and retention KAE for each group is presented in Table 1.

Results of an analysis of variance Indicate that the effect of number of I-periods is significant at the .01 level $(F=5.17$, $d f=2 / 225)$. Further analysis indicates that the increase between the five period and ten period conditions $(2.5 \mathrm{~min}$, and $5 \mathrm{~min}$. inspection) is significant $(p<.01)$. There is a nonsignificant decrease in KAE between the ten and fifteen period conditions (5 and $7.5 \mathrm{~min}$. inspection).

Spacing of I-periods was not a significant variable, though there was a tendency for the massed condition to produce smaller KAEs. The 15-min, interval between the post-inspection judgments and the retention judgments produced no significant reduction of the aftereffect. None of the interaction effects reached statistical significance.

\section{EXPERIMENT 2}

This experiment was designed to further explore the effect of distribution of inspection periods. It is in part a modified replication of the first experiment together with an extension to study the effect of distribution of I-periods on retention of KAE $24 \mathrm{hr}$. later, and on relnduction of the KAE by additional inspection.

\section{Method}

The procedure was essentially the same as that in the flrst experiment, except for the following differences: (a) The maximum width of the tapered block was reduced from 2.875 in. to $2.3125 \mathrm{in}$. (b) All Ss received the same total inspection time, 5 min., in the form of ten 30-sec. I-periods, separated by either 0,10 , or 30 sec. There were thus three groups with $30 \mathrm{Ss}$ in each. (c) Judgments were made in an ADDA order instead of the ADAD order, and judgments were made with the thumb and index finger rather than the thumb and middle finger. (d) The starting point for each judgment was located at a width of either 1.25 in. or 1.75 in., i.e., 8 in. above or below the point of subjective equality, instead of at either extreme of the variable block. (e) Ss were allowed four practice trials in the ADDA order instead of two. (f) Immediately after the $24 \mathrm{hr}$. retention trials, a single 60-sec. I-period was introduced, followed by a measure of the PSE, the mean of four settings in the ADDA order. This was done to see if the increase in size of the KAE after some decay was related to the distribution of inspection trials on the first day.

\section{Resuits}

The results in terms of the original $\mathrm{KAE}$, retention KAE after $24 \mathrm{hr}$., and the KAE reinduced by additional inspection are presented in Table 2.

Analysis of variance showed no significant differences between the three groups in size of the KAE induced by the three distributions of ten $30-\mathrm{sec}$. I-periods. There was no significant difference in retention of the $\mathrm{KAE}$ after $24 \mathrm{hr}$., and there was no significant difference in the amount of KAE reinstated after the additional 60-sec. inspection period.

Sign test analyses for the three groups taken together show that a significant KAE was induced on the first day by the $5 \mathrm{~min}$. of inspection; 83 of the 90 Ss had KAEs on Day $1(p<.01)$. There was significant partial decay of the KAE over $24 \mathrm{hr}$., with 59 of the 90 Ss showing some decay $(p<.01)$. The decay was partial since there was a significant residual KAE after $24 \mathrm{hr}$., with 75 of the $90 \mathrm{Ss}$ showing some residual $\operatorname{KAE}(p<.01)$. The correlation between size of the residual KAE and the size of the KAE induced on the first day was .70 (Pearson), significant at the .01 level. The reinstatement of the KAE was significant, with 65 of the $90 \mathrm{Ss}$ showing an increase in PSE after the additional $60-\mathrm{sec}$. inspection period $(\mathrm{p}<.01)$.

\section{DISCUSSION}

Despite a wider range of distribution conditions, total inspection time, and other procedural differences, the results of these experiments support those of Carlson (1963) in finding no relationship between distribution of I-periods and either size or retention of KAE. In a risual study involving change in the Müller-Lyer illusion as a function of inspection, Mountjoy (1958) found no effect of distribution of the inspection period. In contrast to these negative results is the finding by Thetford (1963) that massed

Table 2. Mean post-inspection, $24 \mathrm{~h}$ retention, and reinduced KAE (in.) for groups differing in distribution of Hperiods

\begin{tabular}{cccc}
$\begin{array}{c}\text { Time between } \\
\text { l-periods (sec) }\end{array}$ & KAE & $\begin{array}{c}\text { KAE-retention } \\
24 h \text { retention }\end{array}$ & $\begin{array}{c}\text { KAE } \\
\text { Reinduced }\end{array}$ \\
\hline 0 & .17 & .11 & .14 \\
10 & .14 & .09 & .14 \\
30 & .14 & .09 & .16 \\
\hline
\end{tabular}


inspection of a biased Necker cube prior to inspection of a balanced cube leads to more reversals than spaced inspection. The reasons for the discrepancy are not clear, and procedural differences make it hard to compare the studies. One may also question the assumption that a common satiation mechanism determines these various effects.

The present study also shows that with an increase in inspection time there is a point where KAEs stop growing in size and may even start to diminish. It has been shown that these effects increase as inspection time goes from 10 to $60 \mathrm{sec}$. (Bakan, Myers, \& Schoonard, 1962). Carlson (1963) found an increase within the 1 to $5 \mathrm{~min}$. range of inspection time. The present study shows an increase in the KAE between 2.5 and 5 min.; but as inspection time is increased from 5 to $7.5 \mathrm{~min}$., there is no significant increase; in fact, there is a decrease which, though not statistically significant, occurs in all but the $10 \mathrm{sec}$. spacing condition. Such a decrease is compatible with the Idea of Köhler and Fishback (1950b) that there might be a splllover of satiation to the "wrong" places, thus resulting in a reduced aftereffect as a result of prolonged satiation. But they would also predict that such spillover would be inhibited by spaced inspection or satiation. For this there is no support in the present data.

\section{References}

Bakan, P., Myers, L. B., \& Schoonard, J. Kinesthetic aftereffects and length of inspection period. Amer. J. Psychol., 1962, 75, 457-461.

Carlson, J. B. Effect of amount and distribution of inspection time and length of decay interval on kinesthetic aftereffect. $J$. exp. Psychol., 1963, 66, 377-382.

Duncan, C. P. On the similarity between reactive inhibition and neural satiation. Amer. J. Psychol., 1956, 69, 227-235.

Kobler, W., \& Fishback. J. The destruction of the Muller-Lyer illusion in repeated trials: I. An examination of two theories. J. exp. Psychol., 1950a, 40, 267-281.

Kohler, W., \& Fishback, J. The destruction of the Muller-Lyer illusion in repeated trials: II. Satiation patterns and memory traces. J, exp. Psychol, 1950b, 40, 398-410.

Mountjoy, P. T. Effects of exposure time and intertrial interval upon decrement to the Muller-Lyer illusion. J. exp. Psychol., 1958, 56, 97-102.

Thetford, P. E. Influence of massing and spacing on Necker cube reversals. Percept. mot. Skills, 1963, 16, 215-222.

\section{Notes}

1. This research was supported in part by grants from the National Sclence Foundation,

2. Now at Ohio University.

(Accepted for publication March 29, 1967.) 